\title{
Bài học cho doanh nhân phải dựng văn hóa doanh nghiệp - Yếu tố quyết định sự trường tồn của doanh nghiệp
}

\author{
Phan Quốc Việt \& Nguyễn Huy Hoàng
}

Câu lạc bộ Doanh Nhân

February 4, 2019

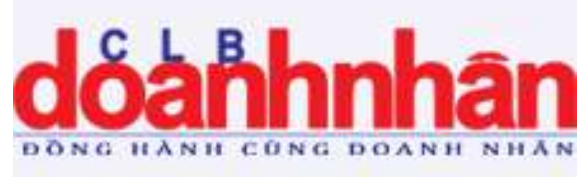

http://www.clbdoanhnhan.vn/bai-hoc-cho-doanh-nhan-phai-dung-van-hoa-doanhnghiep-yeu-to-quyet-dinh-su-truong-ton-cua-doanh-nghiep.html 


\section{dóąăhhnhhân}

Nhập từ khóa cân tìm

HỌI DOANH NHÂN

HọI BÁT ĐỌNG SẢN

SÀN TRỰC TUYÉN

f $\mathrm{G}+\frac{\mathrm{V}_{\text {oun }}}{\text { Tube }}$

\section{BÀI HỌC CHO DOANH NHÂN PHẢI DỰNG VĂN HÓA DOANH NGHIẸP - YÊU TỐ QUYÊT ĐỊNH SỰ TRƯỜNG TÔN CỦA DOANH NGHIẸP}

\section{帮 Thứ hai, 09:42 Ngày 04/02/2019}

Trong một doanh nghiệp, đặc biệt là những doanh nghiệp có quy mô lớn, là một tập hợp những con người khác nhau về trình độ chuyên môn, trình độ văn hóa, mức độ nhận thức, quan hệ xã hội, vùng miền địa lý, tư tưởng văn hóa... chính sự khác nhau này tạo ra một môi trường làm việc đa dạng và phức tạp. Bên cạnh đó, với sự cạnh tranh gay gắt của nền kinh tế thị trường và xu hướng toàn cầu hóa, buộc các doanh nghiệp để tồn tại và phát triển phải liên tục tìm tòi những cái mới, sáng tạo và thay đổi cho phù hợp với thực tế.

Vậy làm thế nào để doanh nghiệp trở thành nơi tập hợp, phát huy mọi nguồn lực con người, làm gia tăng nhiều lần giá trị của từng nguồn lực con người đơn lẻ, góp phần vào sự phát triển bền vững $\mathrm{c}$

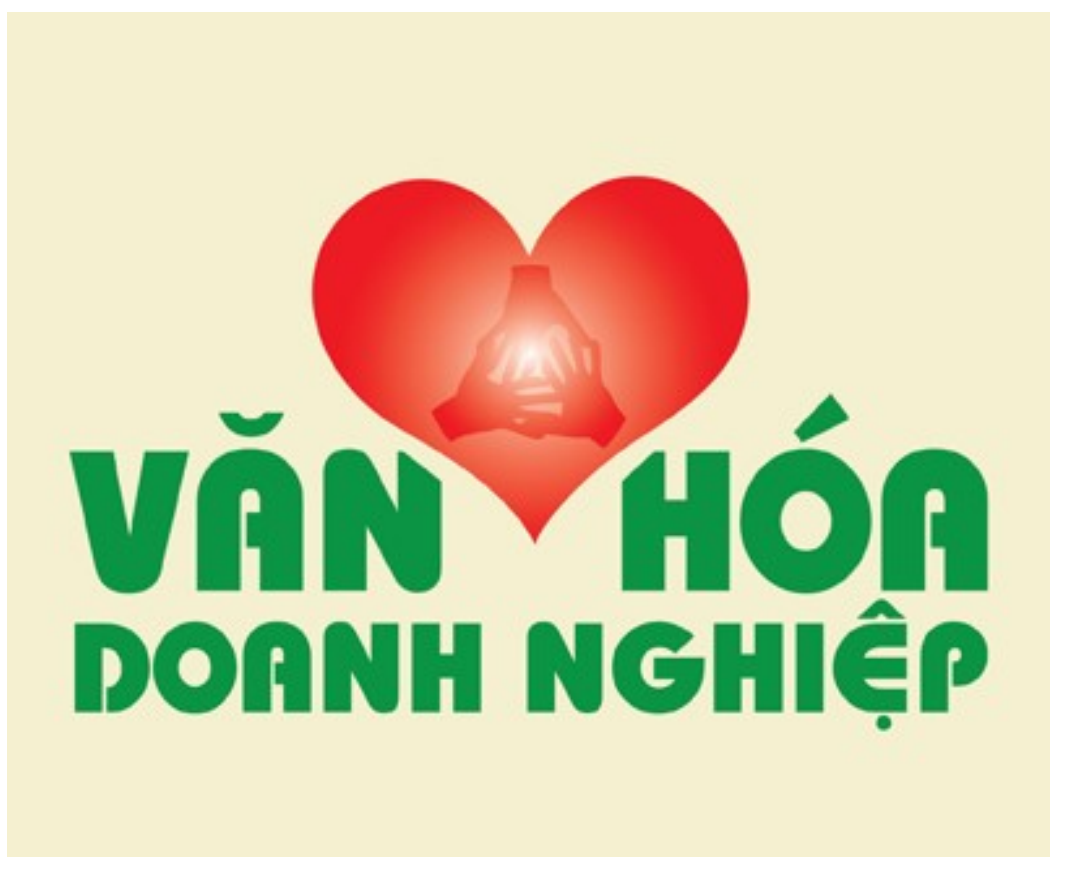


Mặt khác xây dựng VHDN còn là một yêu cầu tất yếu của chính sách phát triển thương hiệu vì thông qua hình ảnh văn hóa doanh nghiệp sẽ góp phần quảng bá thương hiệu của doanh nghiệp. VHDN chính là tài sản vô hình của mỗi doanh nghiệp.

\section{Khái niệm văn hóa doanh nghiệp}

Bất kỳ một doanh nghiệp nào nếu thiếu đi yếu tố văn hóa, tri thức thì khó đứng vững được. VHDN là văn hoá của một tổ chức vì vậy nó không đơn thuần là văn hoá giao tiếp hay văn hoá kinh doanh như ta thường nghĩ. VHDN không phải là những khẩu hiệu của ban lãnh đạo được treo trước cổng, trên hành lang hay trong phòng họp. Đó chỉ là ý muốn, ý tưởng. Những gì chúng ta mong muốn có thể rất khác với những giá trị, niềm tin, chuẩn mực được thể hiện trong thực tế và trong các hành vi mỗi thành viên doanh nghiệp.

\section{Văn hóa doanh nghiệp là gì?}

Có rất nhiều định nghĩa xung quanh khái niệm này. Mỗi nền văn hóa khác nhau có các định nghĩa khác nhau. Mỗi doanh nghiệp lại có một cách nhìn khác nhau về VHDN. Hiện có trên 300 định nghĩa khác nhau về VHDN. Có một vài cách định nghĩa VHDN như sau:

"Phẩm chất riêng biệt của tổ chức được nhận thức phân biệt nó với các tổ chức khác trong lĩnh vực". (Gold, K.A.)

"Văn hóa thể hiện tổng hợp các giá trị và cách hành xử phụ thuộc lẫn nhau phổ biến trong doanh nghiệp và có xu hướng tự lưu truyền, thường trong thời gian dài". (Kotter, J.P. \& Heskett, J.L.)

"Văn hóa doanh nghiệp là những niềm tin, thái độ và giá trị tồn tại phổ biến và tương đối ổn định trong doanh nghiệp". (Williams, A., Dobson, P. \& Walters, M.) 
Còn nếu nói nôm na: Nếu doanh nghiệp là máy tính thì văn hóa doanh nghiệp là hệ điều hành. Nói một cách hình tượng thì: Văn hóa là cái còn thiếu khi ta có tất cả, là cái còn lại khi tất cả đã mất.

Tuy nhiên, mọi định nghĩa đều có nét chung coi VHDN là toàn bộ các giá trị văn hóa được xây dựng trong suốt quá trình tồn tại và phát triển của doanh nghiệp, chi phối tình cảm, nếp suy nghĩ và hành vi của mọi thành viên của doanh nghiệp; tạo nên sự khác biệt giữa các doanh nghiệp và được coi là truyền thống riêng của mỗi doanh nghiệp.

\section{Văn hóa doanh nghiệp, bắt nguồn từ những giá trị}

Cốt lõi của VHDN là tinh thần doanh nghiệp và quan điểm giá trị của doanh nghiệp. Trong cuốn sách Văn mình làm giàu và nguồn gốc của cải của TS. Vương Quân Hoàng, chúng ta đã được đề cập tới khái niệm giá trị. Giải thích một cách đơn giản, giá trị là một cái gì đó mà người ta cảm thấy quan trọng, có ích. Cụm từ "Quan trọng" và "Có ích lợi" là rất đáng lưu tâm trong xây dựng văn hóa doanh nghiệp. Bởi lẽ lãnh đạo công ty sẽ rất khó xây dựng văn hóa doanh nghiệp, nếu không truyền đạt được những ích lợi mà văn hóa doanh nghiệp đem lại. Nhân viên cần được giáo dục nhận thức rằng việc đeo thẻ nhân viên, mặc đồng phục là thể hiện sự tự hào là thành viên của công ty, và có ích cho công việc của họ chứ không phải họ mang những thứ đó để làm quảng cáo.

Rất nhiều lãnh đạo đã mắc lỗi khi áp đặt văn hóa mà không khơi gợi nhận thức của nhân viên mình với các giá trị văn hóa. Nếu không giảng giải được cặn kẽ hệ thống các giá trị văn hóa của doanh nghiệp có ích lợi gì với nội bộ tổ chức, tất yếu moi hình thức triển khai chỉ là phong trào. Một câu hỏi được đặt ra rằng, vậy những giá trị nào là hợp lý và giá trị nào là không hợp lý. Điều này tùy thuộc rất nhiều vào từng tổ chức riêng biệt, nhưng tựu chung lại, có một số giá trị được đề cao trong nội bộ tổ chức ở Việt Nam đó là:

- Sự thành thực (thể hiện là nói thật, không gian dối, cam kết thực hiện những gì mình hứa hẹn và đảm bảo đúng những gì mình sẽ thực hiện)

- Sự tự giác (thể hiện ở mức độ sẵn sang với công việc, không ngại khó khăn, làm việc hết mình vì lợi ích của tổ chức)

- Sự khôn khéo (biết nói những gì cần nói, hỏi những điều cần hỏi, tranh luận những điều đáng tranh luận và sắp xếp những gì hợp lý nhất) 
Ngoài ra còn một số giá trị khác được đề cập tới như sự tự tin, sáng tạo ... Những giá trị này sẽ là nền tảng định hướng cho văn hóa của doanh nghiệp.

Văn hóa có cả biểu hiện hữu hình và vô hình.

Một số biểu hiện rất dễ quan sát, đó là lớp bề mặt của văn hóa, còn phần lõi có ảnh hưởng sâu và mạnh hơn rất nhiều thì vô hình.

\section{Lớp bề mặt của VHDN: Biểu hiện hữu hình}

- Trang phục làm việc

- Môi trường làm việc

- Lợi ích

- Khen thưởng

- Đối thoại

- Cân bằng công việc - cuộc sống

- Mô tả công việc

- Cấu trúc tổ chức

- Các mối quan hệ

\section{Phần lõi: Biểu hiện vô hình}

- Các giá trị

- Đối thoại riêng

- Các quy tắc vô hình

- Thái độ

- Niềm tin

- Quan sát thế giới-

- Tâm trạng và cảm xúc

- Cách hiểu vô thức

- Tiêu chuẩn

- Giả định 
Bản chất của VHDN là đối nội phải tăng cường tiềm lực, quy tụ được sức sáng tạo của công nhân viên chức, khích lệ họ sáng tạo ra nhiều lợi nhuận cho doanh nghiệp; đối ngoại phải được xã hội bản địa chấp nhận.

Văn hóa doanh nghiệp được thể hiện ở nhiều cấp độ khác nhau. Cấp dễ thấy nhất thể hiện ngay trong công việc hàng ngày nhưng cách báo cáo công việc, giữ gìn tài sản chung, ngôn ngữ khi giao tiếp với đồng nghiệp, đối tác, khách hàng, các thủ tục hành chính... Cấp thứ hai là các giá trị tinh thần xác định việc phải làm, hành động của mình đúng hay sai, có mang lại lợi ích hay thiệt hại chung hay không. Đây là điều Lãnh đạo doanh nghiệp mong muốn nhận được ở nhân viên và phải xây dựng dần từng bước. Cấp thứ ba là nền tảng cho các hành động chính là niềm tin, nhận thức, suy nghĩ và xúc cảm được coi là đương nhiên ăn sâu trong tiềm thức mỗi cá nhân trong doanh nghiệp. Các ngầm định nền tảng này là nền tảng cho các giá trị và hành động của mỗi thành viên. Văn hóa kinh doanh trong một tổ chức đã tiến đến mức độ cao nhất, trở thành một thứ Đạo, mà từ thế hệ này tới thế hệ khác tôn sùng và làm theo.

\section{Tác dụng của văn hóa doanh nghiệp}

VHDN quyết định sự trường tồn của doanh nghiệp. Nó giúp doanh nghiệp trường tồn vượt xa cuộc đời của những người sáng lập. Nhiều người cho rằng VHDN là một tài sản của doanh nghiệp. Tác dụng của VHDN thể hiện:

\section{Tạo động lực làm việc}

VHDN giúp nhân viên thấy rõ mục tiêu, định hướng và bản chất công việc mình làm. VHDN còn tạo ra các mối quan hệ tốt đẹp giữa các nhân viên và một môi trường làm việc thoải mái, lành mạnh. VHDN phù hợp giúp nhân viên có cảm giác mình làm công việc có ý nghĩa hãnh diện vì là một thành viên của doanh nghiệp. Điều này càng có ý nghĩa khi tình trạng "chảy máu chất xám" đang phổ biến. Lương và thu nhập chỉ là một phần của động lực làm việc. Khi thu nhập đạt đến một mức nào đó, người ta sẵn sàng đánh đổi chọn mức thu nhập thấp hơn để được làm việc ở một môi trường hoà đồng, thoải mái, được đồng nghiệp tôn trọng.

\section{Điều phối và kiểm soát}


VHDN điều phối và kiểm soát hành vi các nhân bằng các câu chuyện, truyền thuyết; các chuẩn mực, thủ tục, quy trình, quy tắc... Khi phải ra một quyết định phức tạp, văn hoá doanh nghiệp giúp ta thu hẹp phạm vi các lựa chọn phải xem xét.

\section{Giảm xung đột}

VHDN là keo gắn kết các thành viên của doanh nghiệp. Nó giúp các thành viên thống nhất về cách hiểu vấn đề, đánh giá, lựa chọn và định hướng hành động. Khi ta phải đối mặt với xu hướng xung đột lẫn nhau thì văn hoá chính là yếu tố giúp mọi người hoà nhập và thống nhất.

\section{Lợi thế cạnh tranh}

Tổng hợp các yếu tố gắn kết, điều phối, kiểm soát, tạo động lực... làm tăng hiệu quả hoạt động và tạo sự khác biệt trên thị trường. Hiệu quả và sự khác biệt sẽ giúp doanh nghiệp cạnh tranh tốt trên thị trường.

\section{3. Đặc trưng của văn hóa doanh nghiệp}

Để dễ hình dung, chúng ta có thể hiểu văn hóa của doanh nghiệp giống như "cá tính" của doanh nghiệp đó. Ở mỗi cá nhân, cá tính giúp phân biệt người này với người khác, "văn hóa" cũng chính là bản sắc riêng giúp một doanh nghiệp không thể lẫn với doanh nghiệp khác dù có cùng hoạt động trong một lĩnh vực và cung cấp những sản phẩm tương tự ra thị trường.

VHDN có ba nét đặc trưng, đó là: 
- VHDN mang "tính nhân sinh", tức là gắn với con người. Tập hợp một nhóm người cùng làm việc với nhau trong tổ chức sẽ hình thành nên những thói quen, đặc trưng của đơn vị đó. Do đó, VHDN có thể hình thành một cách "tự phát" hay "tự giác". Theo thời gian, những thói quen này sẽ dần càng rõ ràng hơn và hình thành ra "cá tính" của đơn vị. Nên, một doanh nghiệp, dù muốn hay không, đều sẽ dần hình thành văn hoá của tổ chức mình. VHDN khi hình thành một cách tự phát có thể phù hợp với mong muốn và mục tiêu phát triển của tổ chức hoặc không. Chủ động tạo ra những giá trị văn hoá mong muốn là điều cần thiết nếu doanh nghiệp muốn văn hóa thực sự phục vụ cho định hướng phát triển chung, góp phần tạo nên sức mạnh cạnh tranh của mình.

- VHDN có "tính giá trị”. Không có VHDN "tốt" và "xấu” (cũng như cá tính, không có cá tính tốt và cá tính xấu), chỉ có văn hoá phù hợp hay không phù hợp (so với định hướng phát triển của doanh nghiệp). Giá trị là kết quả thẩm định của chủ thể đối với đối tượng theo một hoặc một số thang độ nhất định; và những nhận định này được thể hiện ra thành "đúng-sai", "tốt-xấu", "đẹp-xấu"..., nhưng hàm ý của "sai" của "xấu", về bản chất, chỉ là "không phù hợp". Giá trị cũng là khái niệm có tính tương đối, phụ thuộc vào chủ thể, không gian và thời gian. Trong thực tế, người ta hay áp đặt giá trị của mình, của tổ chức mình cho người khác, đơn vị khác, nên dễ có những nhận định “đúng-sai” về văn hoá của một doanh nghiệp nào đó.

- Văn hóa doanh nghiệp có "tính ổn định". Cũng như cá tính của mỗi con người, văn hoá doanh nghiệp khi đã được định hình thì "khó thay đổi”. Qua thời gian, các hoạt động khác nhau của các thành viên doanh nghiệp sẽ giúp các niềm tin, giá trị được tích lũy và tạo thành văn hoá. Sự tích lũy các giá trị tạo nên tính ổn định của văn hoá.

\section{Những yếu tố cấu thành văn hóa doanh nghiệp}

Cấu trúc của VHDN gồm 5 lớp:

- Triết lý quản lý và kinh doanh: Đây là lớp trong cùng và quan trọng nhất của VHDN, bao gồm những triết lý quản lý và kinh doanh cốt lõi nhất, căn bản nhất. Đây là cơ sở xây dựng định hướng hoạt động của doanh nghiệp và chi phối các quyết định quản lý; là niềm tin, là giá trị bền vững không thay đổi bất chấp thời gian và ngoại cảnh. Vì vậy, điều kiện tiên quyết để quá trình xây dựng VHDN thành công là sự cam kết của những người lãnh đạo cao nhất của doanh nghiệp. Bởi, phần quan trọng nhất, trái tim và khối óc của doanh nghiệp nằm ở lớp trong cùng của văn hóa, xin nhắc lại, đó là triết lý kinh doanh, phương châm quản lý của doanh nghiệp và chỉ có những nhà quản lý cao nhất của doanh nghiệp mới đủ khả năng tác động đến lớp văn hóa cốt lõi này. 
- Động lực của cá nhân và tổ chức: Lớp yếu tố quan trọng thứ hai của VHDN chính là các động lực thúc đẩy hành động của các cá nhân, và môi trường "động lực chung" của tổ chức. Các yếu tố động lực này sẽ biểu hiện ra ngoài bằng những hành vi hàng ngày của các cá nhân trong doanh nghiệp.

- Qui trình qui định: Qui trình, qui định, chính sách giúp doanh nghiệp hoạt động ổn định, theo chuẩn. Đây cũng là cấu thành giúp doanh nghiệp đáp ứng các yêu cầu ngày càng cao về chất lượng sản phẩm dịch vụ của doanh nghiệp, góp phần tạo tính ổn định và nâng cao hiệu quả của doanh nghiệp với nỗ lực làm hài lòng khách hàng và xã hội.

- Hệ thống trao đổi thông tin: Đây là lớp cấu thành thứ tư trong văn hoá doanh nghiệp đáp ứng nhu cầu thông tin quản lý đa dạng, đa chiều, chính xác và kịp thời. Hệ thống này cần đảm bảo mọi thông tin cần thiết cho doanh nghiệp đều được thu thập, truyền đạt, lưu trữ và xử lý; đồng thời đảm bảo cho mọi thành viên doanh nghiệp dễ dàng tiếp cận và sử dụng các thông tin cần thiết cho các hoạt động thường nhật cũng như công tác lập kế hoạch, xây dựng định hướng chiến lược.

- Phong trào, nghi lễ, nghi thức: Đây là cấu thành văn hoá bề nổi, phản ánh đời sống, sinh hoạt của công ty. Tuy không trực tiếp ảnh hưởng đến kết quả kinh doanh, nhưng ảnh hưởng của nó đối với mọi hoạt động của doanh nghiệp cũng rất lớn. Nó tuyên truyền phổ biến đường lối, chính sách của công ty, tạo ra sự khác biệt của công ty với bên ngoài, tạo hình ảnh tốt cho công ty trước cộng đồng qua đó góp phần xây dựng thương hiệu ... Do vậy, để thực sự tạo ra "cá tính" của doanh nghiệp, tạo ra sức mạnh canh tranh cho doanh nghiệp, doanh nhân, cán bộ quản lý cấp cao, các nhà lãnh đạo và quản lý các cấp khác phải nhất thiết tham gia vào quá trình xây dựng văn hoá của tổ chức mình.

\section{Các mối quan hệ trong văn hóa doanh nghiệp}

Ba mối quan hệ cơ bản trong VHDN: Mối quan hệ trong nội bộ công ty, với khách hàng, mối quan hệ khác ngoài doanh nghiệp. Điểm nổi bật của những doanh nghiệp thành công là có cách đối xử đẹp với khách hàng, với chính quyền với cả cộng đồng bằng nền văn hóa riêng biệt.

Các mặt của VHDN: Văn hóa hòa nhập bên trong, VH thích ứng với bên ngoài. 


\section{Làm thế nào để xây dựng văn hóa doanh nghiệp}

Thực tế, văn hoá tồn tại khách quan và doanh nghiệp nào cũng có văn hoá của riêng mình. Chỉ có điều văn hoá được thể hiện như thế nào và doanh nghiệp đó có phát hiện ra những giá trị tốt để phát huy và những giá trị chưa tốt để thay đổi hay không. Văn hóa doanh nghiệp bắt nguồn từ những gì nhỏ nhất, cụ thể, không chung chung.

TS. Lê Quân - Chủ tịch Hội đồng chuyên gia EduViet Consultancy cũng đã đưa ra những ví dụ cụ thể để khẳng định tầm quan trọng của VHDN trong đời sống doanh nghiệp. Và theo Ông, trong quá trình xây dựng VHDN, cần chú trọng tới việc xác lập và phát triển các giá trị văn hóa cốt lõi của doanh nghiệp, các phương pháp, kỹ thuật xác định và kiểm soát, phát triển các giá trị cốt lõi trong hệ thống văn hóa của doanh nghiệp. "Hệ thống giá trị cốt lõi là động lực chủ yếu thúc đẩy mọi người làm việc, hạt nhân liên kết mọi người trong doanh nghiệp với nhau, liên kết doanh nghiệp với khách hàng, đối tác của doanh nghiệp, liên kết doanh nghiệp với xã hội nói chung" - Ông Quân khẳng định.

TS. Phạm Văn Phổ - Chuyên gia EduViet Consultancy, nguyên Viện trưởng Viện Nghiên cứu kinh tế và kinh doanh Hà Nội cho rằng: "Xây dựng VHDN là một quá trình kiên nhẫn, lâu dài và đòi hỏi ý chí lớn lao của từng nhà lãnh đạo, cán bộ công ty”. Và theo Ông, để xây dựng văn hóa trong doanh nghiệp, trước hết phải là ý chí xây dựng văn hóa của ban lãnh đạo doanh nghiệp, sau đó phải qua công tác giáo dục để nhân viên hiểu, chấp nhận chia sẻ và đi đến sự đồng thuận trong cộng đồng doanh nghiệp đó. Ngoài ra, muốn xây dựng VHDN thì phải biết phối hợp chặt chẽ giữa các bộ phận trong Công ty. Thiếu sự hợp lực này thì VHDN sẽ không xây dựng được.

TS. Hoàng Đình Phi - Chủ tịch HĐQT EduViet và Chủ tịch HĐQT Tập đoàn Sannam đã đưa ra những cơ sở lý luận cơ bản để xây dựng và phát triển trình độ VHDN và Ông cho rằng: "đã đến lúc các doanh nghiệp Việt Nam nên nghiên cứu và thành lập thêm một bộ phận quản lý mới trong hệ thống quản trị doanh nghiệp để chuyên quản lý về văn hóa doanh nghiệp".

Văn hóa doanh nghiệp có vô vàn hình thức biểu hiện, nhưng cũng xin lưu ý với những nhà tổ chức, muốn xây dựng VHDN rằng, VHDN không phải thực hiện trong ngày một ngày hai, nó có thể là một chặng đường kéo dài hàng thập kỷ, Việc xây dựng VHDN không phải là một khẩu hiệu, nó phải được sự vun đắp của từng cá nhân trong tổ chức doanh nghiệp đó, xây dựng văn hóa là chìa khóa để doanh nghiệp được trường tồn. 


\section{Làm thế nào để xây dựng VHDN?}

Để thấu hiểu từng bước xây dựng VHDN thì ta cùng xem xét mô hình dưới đây. Thoạt nhìn có thể thấy rất phức tạp nhưng thực sự không như vậy. Các mối quan hệ rất rõ ràng và thể hiện cách thức chúng ta đưa một giá trị mong muốn vào doanh nghiệp để mọi người chấp nhận và coi như đương nhiên.

Bên phải mô hình là VHDN dưới dạng quan sát "thấy" được. Còn bên trái là các "phương tiện" để văn hoá doanh nghiệp thể hiện ra ngoài. Bây giờ ta cùng xem xét từng mối quan hệ và cách thức đưa một giá trị mong muốn vào thực tế.

\section{Sơ đồ}

(1) Các vật thể hữu hình (như văn phòng, bàn ghế, tài liệu...) là môi trường mà nhân viên làm việc. Chúng là nhân tố duy trì và có ảnh hưởng trực tiếp lên phong cách làm việc, cách ra quyết định, phong cách giao tiếp và đối xử với nhau. Ví dụ: điều kiện làm việc tốt hơn thì việc giao tiếp cũng sẽ thuận lợi hơn...

(2) Ngược lại phong cách làm việc, ra quyết định, giao tiếp và đối xử có ảnh hưởng trở lại đối với những vật thể hữu hình đó. Phong cách làm việc chuyên nghiệp cần thiết phải được trang bị những công cụ làm việc hiện đại phù hợp. Giao tiếp chủ yếu bằng e-mail thì cần một hệ thống máy vi tính...

(3) Các giá trị được thể hiện được chia thành hai thành phần. Thành phần thứ nhất là các giá trị tồn tại một cách tự nhiên. Một số trong các giá trị đó được coi là đương nhiên chúng ta gọi đó là các ngầm định. Thành phần thứ hai là các giá trị chưa được coi là đương nhiên và các giá trị mà lãnh đạo mong muốn đưa vào doanh nghiệp mình. Những giá trị được các thành viên chấp nhận thì sẽ tiếp tục được duy trì theo thời gian và dần dần được coi là đương nhiên. Sau một thời gian đủ lớn thì các giá trị này trở thành các ngầm định theo mối quan hệ 6.

(4) Tuy nhiên, các nhân viên rất nhạy cảm với sự thay đổi môi trường làm việc và các giá trị mà lãnh đạo đưa vào. Thông thường sự thay đổi này thường bị từ chối. Các giá trị không được nhân viên thực hiện sẽ phải thay đổi hoặc loại bỏ khỏi danh sách các giá trị cần đưa vào. 
(5) Các ngầm định thường khó thay đổi và ảnh hưởng rất lớn đến phong cách làm việc, quyết định, giao tiếp và đối xử. Sự ảnh hưởng của các ngầm định còn lớn hơn rất nhiều so với sự ảnh hưởng của các giá trị được thể hiện.

(6) Một khi các giá trị được kiểm nghiệm qua phong cách làm việc, quyết định, giao tiếp, đối xử nếu các giá trị đó là phù hợp và từng bước dần dần được coi là đương nhiên thì nó sẽ trở thành ngầm định. Và đến đây việc đưa một giá trị mong muốn vào doanh nghiệp thành công.

Ví dụ: Một doanh nghiệp muốn tất cả nhân viên của mình đều làm việc đúng giờ. Ban đầu có thể sẽ có một số người phản đối. Các biện pháp khuyến khích, ép buộc được thực hiện một cách thích hợp sẽ tạo ra một nề nếp (mặc dù có đôi chút ép buộc). Theo thời gian, việc làm việc đúng giờ dần trở thành thói quen. Cho đến khi nó trở thành phản xạ tự nhiên và mọi người cảm thấy hãnh diện vì điều đó. Lúc đó giá trị này đã trở thành ngầm định. Các nhân viên mới vào doanh nghiệp cũng thấy ngay phong cách làm việc đúng giờ, hòa mình theo để thể hiện mình là thành viên của doanh nghiệp.

Qua mô hình này ta đã có thể hình dung ra ngay cách xây dựng văn hoá doanh nghiệp. Tất nhiên đây là một quá trình đòi hỏi nỗ lực không chỉ từ phía lãnh đạo mà phải từ tất cả các thành viên trong doanh nghiệp.

Xây dựng văn hoá doanh nghiệp là một quá trình tổng thể chứ không phải chỉ là việc đưa một giá trị một cách đơn lẻ rời rạc. Vậy để xây dựng văn hoá doanh nghiệp một cách tổng thể thì cần theo những bước cụ thể nào?

Có nhiều mô hình được các nhà nghiên cứu đề xuất. Tuy nhiên là doanh nhân, chúng ta cần những bước thực tế, cụ thể. Hai tác giả Julie Heifetz \& Richard Hagberg đã đề xuất một mô hình 11 bước cụ thể như sau:

1. Tìm hiểu môi trường và các yếu tố ảnh hưởng đến chiến lược doanh nghiệp trong tương lai. Xem xét có yếu tố nào làm thay đổi chiến lược doanh nghiệp trong tương lai.

2. Xác định đâu là giá trị cốt lõi làm cơ sở cho thành công. Đây là bước cơ bản nhất để xây dựng văn hoá doanh nghiệp. Các giá trị cốt lõi phải là các giá trị không phai nhòa theo thời gian và là trái tim và linh hồn của doanh nghiệp. 
3. Xây dựng tầm nhìn mà doanh nghiệp sẽ vươn tới. Tầm nhìn chính là bức tranh lý tưởng về doanh nghiệp trong tương lai. Tầm nhìn chính là định hướng để xây dựng văn hoá doanh nghiệp. Có thể doanh nghiệp mà ta mong muốn xây dựng hoàn khác biệt so với doanh nghiệp hiện mình đang có.

4. Đánh giá văn hóa hiện tại và xác định những yếu tố văn hoá nào cần thay đổi. Sự thay đổi hay xây dựng văn hoá doanh nghiệp thường bắt đầu bằng việc đánh giá xem văn hoá hiện tại như thế nào và kết hợp với chiến lược phát triển doanh nghiệp. Đánh giá văn hoá là một việc cực kỳ khó khăn vì văn hoá thường khó thấy và dễ nhầm lẫn về tiêu chí đánh giá. Những ngầm định không nói ra hay không viết ra thì càng khó đánh giá. Thường thì con người hoà mình trong văn hoá và không thấy được sự tồn tại khách quan của nó.

5. Khi chúng ta đã xác định được một văn hoá lý tưởng cho doanh nghiệp mình và cũng đã có sự thấu hiểu về văn hoá đang tồn tại trong doanh nghiệp mình. Lúc này sự tập trung tiếp theo là vào việc làm thế nào để thu hẹp khoảng cách giữa những giá trị chúng ta hiện có và những giá trị chúng ta mong muốn. Các khoảng cách này nên đánh giá theo 4 tiêu chí: phong cách làm việc, ra quyết định, giao tiếp, đối xử.

6. Xác định vai trò của lãnh đạo trong việc dẫn dắt thay đổi văn hóa. Lãnh đạo đóng vai trò cực kỳ quan trọng cho việc xây dựng văn hoá. Lãnh đạo là người đề xướng và hướng dẫn các nỗ lực thay đổi. Lãnh đạo chịu trách nhiệm xây dựng tầm nhìn, truyền bá cho nhân viên hiểu đúng, tin tưởng và cùng nỗ lực để xây dựng. Lãnh đạo cũng đóng vai trò quan trọng trong việc xua tan những mối lo sợ và thiếu an toàn của nhân viên.

7. Khi khoảng cách đã được xác định thì việc tiếp theo là soạn thảo một kế hoạch hành động bao gồm các mục tiêu, hoạt động, thời gian, điểm mốc và trách nhiệm cụ thể. Cái gì là ưu tiên? Đâu là chỗ chúng ta cần tập trung nỗ lực? Cần những nguồn lực gì? Ai chịu trách nhiệm về những công việc cụ thể? Thời hạn hoàn thành?

8. Phổ biến nhu cầu thay đổi, kế hoạch hành động và động viên tinh thần, tạo động lực cho sự thay đổi. Sự thay đổi sẽ ảnh hưởng đến đời sống nhân viên. Họ cần được biết sự thay đổi đó đem lại điều tốt đẹp cho họ. Sự động viên, khuyến khích sẽ dễ dàng hơn khi mọi người được biết vai trò của mình là đóng góp và xây dựng tương lai doanh nghiệp.

9. Nhận biết các trở ngại và nguyên nhân từ chối thay đổi và xây dựng các chiến lược để đối phó. Lôi kéo mọi người ra khỏi vùng thoải mái của mình là một công việc rất khó. Vì vậy người lãnh đạo phải khuyến khích, động viên và chỉ cho nhân viên thấy lợi ích của họ tăng lên trong quá trình thay đổi. 
10. Thể chế hóa, mô hình hóa và củng cố sự thay đổi văn hóa. Các hành vi, quyết định của lãnh đạo phải thể hiện là mẫu hình cho nhân viên noi theo và phù hợp với mô hình văn hoá đã xây dựng. Trong gia đoạn các hành vi theo mẫu hình lý tướng cần được khuyến khích, động viên. Hệ thống khen thưởng phải được thiết kế phù hợp với mô hình xây dựng văn hoá doanh nghiệp.

11. Tiếp tục đánh giá văn hóa doanh nghiệp và thiết lập các chuẩn mực mới về không ngừng học tập và thay đổi. Văn hoá không phải là bất biến vì vậy khi ta đã xây dựng được một văn hoá phù hợp thì việc quan trọng là liên tục đánh giá và duy trì các giá trị tốt. Truyền bá những giá trị đó cho nhân viên mới.

Tóm lại, xây dựng VHDN không đơn thuần là liệt kê ra các giá trị mình mong muốn mà đòi hỏi sự nỗ lực của tất cả các thành viên, sự khởi xướng, cổ vũ, động viên của lãnh đạo. Với cách hiểu đúng đắn tổng thể về VHDN và với mười một bước cơ bản này sẽ giúp các doanh nghiệp từng bước xây dựng thành công văn hoá cho mình.

(TS Phan Quốc Việt \& Ths. Nguyễn Huy Hoàng,

Trung tâm Phát triển Kỹ năng Con người Tâm Việt)

\section{Thich 4 Tweet + Share}

\section{BÀI VIÉT LIÊN QUAN}




\section{Đăng ký tại Huấn Luyện Viên} Hotline 0902641618

\section{AN GIA LẠP NGHIẸP dóăhnhnhân}

\section{HộI THẢO HợP TÁC VÀ KINH D}

Chương trình Câu Lạc Bộ Cà Phê Bất Động Sản AGG tại HCN Thời gian: 18h tại Cà Phê 368, Số 222 D5, P. 25, Q. Bi

\section{TRANG CHỦ}

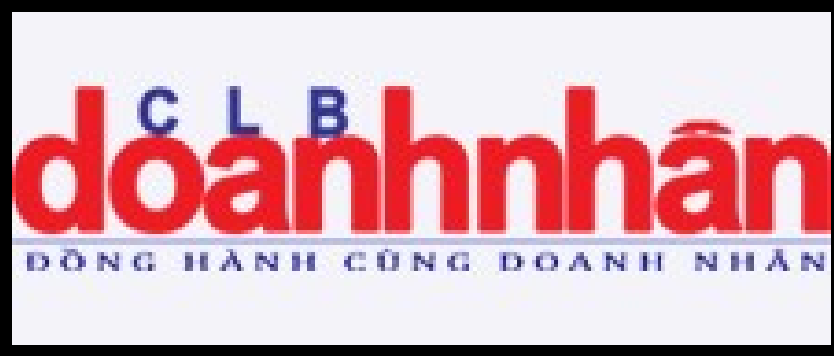

Người chịu Trách nhiệm nội dung: Đỗ Văn Hiếu

Phó trưởng đại diện Đông Nam Bộ, Tạp chí Doanh Nghiệp Hội Nhập

Hotline: 0932074939 - Email: Baodoanhnghiephoinhap@gmail.com

Tòa soạn: Số B101/1 Bình Đức 2, F. Lái Thiêu, Tp. Thuận An, Bình Dương. 
Tài liệu tham khảo:

[1] Đào Duy Anh. (1938). Việt Nam văn hóa sử cương. Quan Hải Tùng Thư, Huế (Imprimerie du Mirador).

[2] Vương Quân Hoàng. (2007). Văn minh làm giàu \& Nguồn gốc của cải. Nxb Chính trị Quốc gia, Hà Nội. 